\title{
GÊNERO E SEXUALIDADE NA EDUCAÇÃO BÁSICA E NA FORMAÇÃO DE PROFESSORES: LIMITES E POSSIBILIDADES
}

\author{
B. S. GUIZZO e D. RIPOLL* \\ Programa de Pós-Graduação em Educação - Universidade Luterana do Brasil \\ daniela_ripoll@terra.com.br*
}

Artigo submetido em abril/2015 e aceito em novembro/2015

DOI: $10.15628 /$ holos.2015.2945

\section{RESUMO}

A partir da perspectiva teórica dos Estudos Culturais e dos Estudos de Gênero, o artigo objetiva analisar e problematizar as maneiras como as questões de gênero e de sexualidade têm sido abordadas na Educação Básica e em cursos de formação de professores. Foram analisadas algumas situações vivenciadas pelas autoras ao longo da pesquisa: um encontro presencial com turmas de $5^{\circ}$ ano de uma escola da rede pública do Rio Grande do Sul, para a discussão de perguntas relacionadas a gênero e sexualidade; entrevistas com as professoras regentes destas turmas; a participação em uma comissão do Programa Nacional do Livro Didático voltada para a análise de livros didáticos de Ensino Médio e, por fim, algumas atividades voltadas à formação de professores no Ensino Superior. Conclui-se que, na Escola Básica, as formas de viver/explorar o corpo e a sexualidade trabalhadas dentro da escola continuam ligadas a questões biológicas e de saúde. Professores e professoras tendem a apoiar-se nessas abordagens mais "científicas" que, de certa forma, restringem a questão da sexualidade à reprodução e reiteram a heteronormatividade. Há pequenos avanços com relação às temáticas de gênero e sexualidade nos livros didáticos analisados, mas há, também, alguns retrocessos que contribuem para a perpetuação de situações de preconceito e de exclusão. Quando instados a pensar sobre tais aspectos e a analisar criticamente como alguns materiais tradicionalmente utilizados nas salas de aula da educação básica constroem determinadas representações sexualizadas e generificadas, os professores em formação encontram, em geral, muitas dificuldades.

PALAVRAS-CHAVE: Estudos Culturais,educação contemporânea, gênero, sexualidade

\section{GENDER AND SEXUALITY IN BASIC EDUCATION AND TEACHER TRAINING: LIMITS AND POSSIBILITIES}

\begin{abstract}
From the theoretical perspective of Cultural Studies and Gender Studies, the paper aims to analyze and discuss the ways in which gender and sexuality issues have been addressed in basic education and teacher training courses. We analyzed some situations experienced by the authors during the research: an in-person meeting with groups of $5^{\text {th }}$ year of a public school in Rio Grande do Sul, for clarification and discussion of questions related to gender and sexuality; interviews with the teachers in these classes; participation in a committee of the Programa Nacional do LivroDidático focused on the analysis of textbooks used in Brazilian schools and, finally, some activities related to teacher training in higher education. In conclusion, the Basic School, the ways of
\end{abstract}

living / explore the body and sexuality worked within the school are still linked to biological and health issues. In general, teachers tend to rely on these approaches more "scientific" which, in a way, restrict the issue of sexuality to reproduction and reiterate heteronormativity. There are small advances with respect to issues of gender and sexuality in the textbooks analyzed, but there are also some setbacks that contribute to the perpetuation of prejudice and exclusion situations. When asked to think about such issues and to critically analyze how some materials traditionally used in classrooms of basic education build certain sexualized and gendered representations, student in training find it very difficult.

KEYWORDS: Cultural Studies, contemporary education, gender, sexuality. 


\section{CONSIDERAÇÕES INICIAIS}

A partir da perspectiva teórica dos Estudos Culturais e dos Estudos de Gênero de viés pósestruturalista, o presente artigo objetiva discutir algumas temáticas sobre as quais temos nos debruçado ao longo de nossas trajetórias acadêmicas e profissionais - temáticas que se articulam e dialogam entre si, quais sejam: gênero, sexualidade e educação. Mais especificamente, objetivamos problematizar as maneiras como as questões de gênero e de sexualidade têm sido abordadas em múltiplos espaços educacionais. Entretanto, antes de determo-nos nesse objetivo, julgamos necessário expor, mesmo que brevemente, alguns entendimentos acerca das referidas temáticas e dos conceitos que a elas se atrelam, a partir das contribuições de autores/as que vêm debruçando-se sobre eles/as.

O conceito de gênero tem contribuído para relativizar, tensionar e problematizar as questões relacionadas às diferenças atribuídas a mulheres e homens, tomadas por muitos/as estudiosos/as, atrelados/as especialmente às áreas da biologia e da saúde, como algo "natural" e "biologicamente" dado. Entretanto, de acordo com os estudos de Joan Scott (1995), gênero é algo que não deve ser ligado fundamentalmente ao determinismo biológico. Por volta dos anos de 1950 e 1960, se intensifica a noção de que não se nasce homem ou mulher, como pontuou Simone de Beauvoir em "O segundo sexo" em 1949, mas sim vão sendo ensinados atributos para que os sujeitos se tornem dessa ou daquela maneira. Partindo disso, é possível afirmar que gênero pode ser considerado como o produto do "trabalho" da cultura, da sociedade sobre a biologia.

Guacira Louro $(1997,2004)$ salienta que esse conceito não se resume à diferenciação de "papéis" e "funções" femininas e masculinas. De acordo com ela ao pensarmos tal conceito simplesmente como sinônimo de papéis, damos margem a se pensar em regras arbitrárias que determinada cultura ou sociedade impõe aos seus membros (definindo comportamentos, modos de ser, modos de se vestir, atitudes, etc.) e deixa-se de problematizar as relações de poder existentes entre homens e mulheres.

Donna Haraway (2004), por sua vez, diz que o conceito de gênero foi desenvolvido com o intuito de contestar e transformar a naturalização da diferença sexual que acaba por posicionar homens e mulheres de maneira diferenciada e, até, hierarquizada.

O conceito de sexualidade, tal como gênero, deve ser pensado para além das ideias vistas como algo essencial ou naturalmente dado. Com isso não queremos negar a biologia, mas enfatizar as construções culturais, sociais e históricas produzidas sobre as características biológicas dos sujeitos no que diz respeito à sexualidade (LOURO, 1997). Jeffrey Weeks (1999) nos auxilia a compreender que mesmo que nossos corpos sejam os lugares de exploração de nossas sexualidades, elas relacionam-se também com nossas ideias, rituais, fantasias, desejos, prazeres e imaginações. Tal compreensão, no entanto, não é facilmente entendida por uma grande gama de sujeitos. Já que ainda nos dias atuais, observam-se resquícios das ideias em torno da sexualidade que circulavam no século XIX. Segundo Foucault (1997), nesse período, tentou-se reduzir a sexualidade à sua função reprodutiva, à sua forma heterossexual e adulta. Outras formas de exercer a sexualidade, que fugiam a essas regras, passaram a ser consideradas "anormais" e/ou "periféricas". Entretanto, não podemos deixar de considerar que a sexualidade dita "normal" e "regular" só é estabelecida a partir dessas outras sexualidades consideradas "anormais", "periféricas". 
Outro entendimento que julgamos importante trazer para o âmbito desse artigo diz respeito à educação. Aqui ela não é compreendida como algo que se limita aos espaços familiar e/ou escolar, mas vai além deles. Steinberg e Kincheloe (2001) argumentam que outras instâncias passaram a ter maior visibilidade no campo educacional e podem ser chamadas de Pedagogias Culturais. Tais Pedagogias incluem a escola, mas vão além dela, abrangendo uma variedade de espaços e de artefatos com os quais temos tido envolvimento na contemporaneidade.Livros, Shopping Centers, filmes, materiais didáticos, salas de cinema, novelas, músicas, desenhos animados acabam por nos ensinar e educar sobre uma infinidade de coisas. Entretanto, esses espaços e artefatos ainda são poucos articulados àquilo que se propõe dentro das escolas. Talvez pudéssemos firmar mais do que isso: as escolas não têm conseguido mudar, inovar e trazer para seus âmbitos temáticas que estão presentes quase que diariamente na vida de crianças e jovens, dentre essas as que aqui nos interessam: corpo, gênero e sexualidade. Sendo assim, nesse artigo, pretendemos discutir a seguinte problemática: de que modo as questões de gênero e sexualidade têm sido trabalhadas no âmbito da educação básica e nos cursos de formação docente?

As análises culturais processadas no presente artigo caracterizam-se como operações voltadas para a desnaturalização de artefatos ou práticas"comuns", "banais" e "insuspeitos" em nossas vidas cotidianas. Em uma análise cultural, o pesquisador faz um exercício exaustivo para tornar singular algo que, aparentemente, é ordinário e que, por uma razão (ou várias), "desapareceu" na poeira do cotidiano(NELSON; TREICHLER; GROSSBERG, 1995; WILLIS, 1997; WORTMANN, 2002).O ponto crucialé conseguir identificar "quando e como ele [o objeto, o artefato, a prática] se torna suficientemente visível para ser objeto concreto de análise" (WILLIS, 1997, p. 111) - é poder tornar visíveis objetos, artefatos, relações e práticas que, em certo momento, tornaram-se invisíveis.

\section{QUANDO AS QUESTÕES DE SEXUALIDADE ENTRAM NA ESCOLA}

Como sabemos, a escola - enquanto instituição educacional formal - é uma invenção que se deu por volta do final do século XVI, mas a estrutura física, a forma como são desenvolvidas as aulas, os conteúdos propostos e a organização curricular posta em ação ainda em muito se assemelham àqueles de séculos atrás.

Entretanto, há uma visível (e talvez mais importante) diferença entre as escolas modernas e as escolas contemporâneas: os alunos que as frequentam. Hoje os alunos têm acesso a inúmeros artefatos culturais através dos quais, como apontamos anteriormente, também aprendem, produzem conhecimento e interagem, a saber: a televisão, os aparelhos de celular, os computadores, etc. Sendo assim, temos alunos do século XXI, dentro de uma instituição pensada para os séculos XVI e XVII, o que leva alguns estudiosos a falarem em crise da escola (GREEM e BIGUM, 2009; COSTA, 2006).

Tal crise estaria sendo desencadeada justamente por não estarmos levando para o âmbito escolar assuntos que efetivamente despertem o interesse e satisfaçam as necessidades desses alunos contemporâneos. Atentos a isso, sujeitos vinculados ao campo educacional (pesquisadores, professores, estudantes), especialmente a partir da segunda metade do século XX, começaram a contestar e a questionar a forma como a educação vinha se dando. Paralelamente a isso, vários 
grupos sociais e culturais passaram a reivindicar o direito à representação ${ }^{1}$ e a questionar as formas de conhecimento dominantes. E essas reivindicações surgem quando esses grupos não se reconhecem como iguais a partir de processos de desigualdade, produzidos a partir de diferenças como gênero, sexualidade, raça, cor, classe social, etc. que se dão em diferentes espaços, incluindo-se - certamente - a escola.

Levando em conta esses aspectos, nesse artigo nosso principal propósito - como já mencionado - é discutir e problematizar as formas como as temáticas de gênero e de sexualidade têm sido (ou não!) abordadas no interior das escolas. Antes, porém, faz-se necessário destacar que no Brasil, especialmente a partir da década de 1990, alguns documentos oficiais legais passaram a ser pensados e produzidos a fim de dar visibilidade a questões que até então não eram consideradas como "próprias" para serem abordadas com crianças e jovens. Dentre esses documentos, destacamos: a) os Parâmetros Curriculares Nacionais (PCNs), elaborados e propostos pelo Ministério da Educação (MEC) em 1998 cujo propósito voltava-se para o apoio às temáticas e às discussões que poderiam ser desenvolvidas nas escolas; b) as Diretrizes Curriculares Nacionais Gerais para a Educação Básica (DCNs) que visam orientar o planejamento curricular das instituições de ensino. Importante destacar que essas Diretrizes são normas obrigatórias, fixadas desde 1996 e revisadas em 2010 pelo Conselho Nacional de Educação $(C N E)^{2}$. Sendo obrigatórias, as DCNs deveriam pautar as ações pedagógicas nas escolas. As temáticas de gênero e de sexualidade, no entanto, aparecem como transversais, motivo pelo qual - não raro - acabam sendo esquecidas e/ou pouco trabalhadas/exploradas.

Com o surgimento de documentos tais como os que supracitamos, mesmo que ainda timidamente, a escola tem sido palco de situações e de aprendizagens relacionadas a temáticas que há bem pouco tempo eram impensadas para seu âmbito. No entanto, mesmo que há aproximadamente duas décadas os referidos documentos venham sendo pensados, elaborados e propostos, algumas temáticas neles mencionadas, quando efetivamente levadas para dentro da escola, ainda geram conflitos, resistências e estranhamentos.

Temos tido a oportunidade de circular nesses ambientes em função das pesquisas que realizamos e dos estágios curriculares que supervisionamos. E deparamo-nos com situações que envolvem as questões de sexualidade e que merecem ser discutidas e problematizadas. Em uma de nossas pesquisas estão sendo realizadas entrevistas com professoras que atuam na Educação Básica. Na entrevista realizada com duas professoras regentes de turmas do $5^{\circ}$ ano cuja faixa etária dos alunos varia entre 10 e 15 anos, elas salientaram que, desde 2006, desenvolvem um projeto que envolve tanto as questões de gênero, quanto as de sexualidade.

A escola em que elas trabalham atende alunos oriundos de grupos familiares cuja renda salarial é baixa, bem como alunos que vivem em abrigos destinados a crianças e jovens abandonados ou vítimas de maus tratos e/ou abusos sexuais.

Segundo elas, todos os cuidados são tomados a fim de não gerar polêmicas ou mal entendidos: é feita uma sondagem para verificar o interesse dos alunos sobre as temáticas de gênero e sexualidade, a equipe diretiva é informada a respeito do trabalho a ser desenvolvido e

\footnotetext{
${ }^{1}$ Valemo-nos do conceito de representação de Hall (1997, p. 61) para quem "a representação é o processo pelo qual membros de uma cultura usam a linguagem para instituir significados. Essa definição carrega uma premissa: as coisas, os objetos, os eventos do mundo não têm, neles mesmos, qualquer sentido fixo, final ou verdadeiro".

${ }^{2}$ As DCNs tiveram origem na Lei de Diretrizes e Bases da Educação (LDB) de 1996 (Lei Federal 9.394/1996).
} 
bilhetes cujo conteúdo expressa os objetivos e as razões do referido projeto são enviados aos responsáveis. De modo geral, os alunos gostam bastante das atividades que fazem parte desse projeto. Entretanto, em praticamente todos os anos, há pais, mães e responsáveis que se contrapõem a ele, tanto que não permitem a participação de seus filhos em determinadas atividades.

Uma das atividades que faz parte do projeto é bastante conhecida da maioria dos professores e professoras que atuam na educação básica e desenvolve-se da seguinte maneira: depois de serem explorados alguns assuntos que fazem parte do projeto, uma caixinha é colocada na sala de aula para que os alunos depositem suas dúvidas e perguntas a respeito do que foi trabalhado. A identificação do que é aí depositado fica restrita às professoras. A culminância dessa atividade se dá quando um profissional que não faz parte da escola, vai até lá para conversar sobre o conteúdo da caixinha.

Diferentemente de anos anteriores, em que geralmente esse profissional era vinculado à área da saúde e ia até a escola para conversar com os alunos, uma de nós foi convidada a fazê-lo. O convite foi aceito e antes do encontro presencial com as turmas do $5^{\circ}$ ano, recebemos as perguntas para termos uma ideia a respeito do que falaríamos. Dentre essas perguntas, destacamos as seguintes:

Por que a mulher fica menstruada? O que é espermatozoide? O que é fecundação? O que é progesterona? O que é púbis? O que é ejaculação? O que é "afogar o ganso"? Pode uma mulher engravidar na primeira vez? A menstruação tem cheiro? Como podemos saber quando nosso corpo se move durante a transa? Qual a idade que meninas ficam menstruadas? É normal que a primeira ejaculação ocorra durante o sono? O que acontece quando um bebê nasce prematuro? O que é relação sexual? Quais são as piores doenças sexualmente transmissíveis?

De acordo com as professoras, os assuntos que permeavam tais perguntas já haviam sido trabalhados por elas junto com as turmas. Partindo dessa colocação, percebemos que as formas de viver/explorar o corpo e a sexualidade trabalhadas dentro da escola ainda continuam ligadas a questões biológicas e de saúde. De modo geral, professores e professoras tendem a apoiar-se nessas abordagens mais "científicas" que, de certa forma, restringem a questão da sexualidade à reprodução. Em consequência disso, há a reiteração de que há uma única forma sadia e normal de se viver a sexualidade: a heterossexual (LOURO, 2002). Na medida em que aquilo que a escola propõe liga-se, mesmo que involuntariamente, apenas a essas abordagens em que a heterossexualidade é colocada no centro, outras maneiras de viver a sexualidade acabam sendo negadas e postas à margem.

De qualquer forma, a existência de algumas perguntas aparentemente pouco relacionadas aos discursos biológicos e biomédicos - como: $O$ que é afogar o ganso? Como podemos saber quando nosso corpo se move durante a transa? (provavelmente atrelada à sensação que um sujeito tem ao chegar ao orgasmo) - constituem-se em exemplos de como o discurso do senso comum resiste, ignora e, da mesma forma, tensiona as supostas "verdades" científicas ensinadas na escola ${ }^{3}$.

\footnotetext{
${ }^{3}$ É importante salientar que, nesta atividade de pesquisa, grande parte das discussões articulou-se muito mais à sexualidade (e ao ato sexual em si) do que ao gênero.
} 
Importante destacar também que durante a conversa outras questões, além das colocadas na caixinha, foram feitas. Um dos aspectos trabalhados ao longo da conversa relacionou-se ao fato de que a sexualidade não se vincula apenas a prevenção de gravidez e doenças. Procuramos mencionar que ela pode ser, através de nossos corpos, fonte de desejo, prazer e satisfação e não apenas de reprodução (WEEKS, 1999). Uma vez que a sexualidade não se restringe à reprodução, expomos aos alunos que ela pode ser vivida de variadas formas: com o próprio corpo, no corpo do outro (sendo do sexo oposto ou não). A partir dessa colocação, alguns alunos sentiram-se encorajados a fazer questionamentos e comentários a respeito de conhecidos, familiares, personalidades e amigos cuja orientação sexual era homossexual:

"dois homens podem se casar?", "eu tenho duas vizinhas que são casadas", "na novela tem dois homens que são casados e querem ter filho", "meu tio tem um namorado ... minha mãe diz que foi o jeito que ele encontrou de ser feliz".

Essas são perguntas e falas que possivelmente não surgiriam caso a abordagem da conversa fosse meramente vinculada à biologia e à saúde. Alunos e alunas, através dessas falas, parecem já entender que há outras possibilidades de se viver o gênero e a sexualidade e que, além disso, ser heterossexual não é algo tão "natural" como ainda se tem procurado reiterar.

Ao final da conversa, as professoras comentaram que a atividade durou além do previsto (quase duas horas), pois os alunos perguntaram bastante e realmente mostraram-se envolvidos com o que foi desenvolvido. Elas, no entanto, lamentaram que dos 47 alunos que frequentam as duas turmas de 50 anos, apenas 25 compareceram naquele dia, pois quase metade deles não teve autorização para participar da atividade.

\section{QUANDO AS QUESTÕES DE GÊNERO E SEXUALIDADE ENTRAM NOS LIVROS DIDÁTIVOS DE BIOLOGIA E NA FORMAÇÃO DE PROFESSORES}

Desde a proposição dos Parâmetros Curriculares Nacionais do Ensino Médio ${ }^{4}$ (PCNEM) Parte III - Ciências da Natureza, Matemática e suas Tecnologias (BRASIL, 2000) enfatiza-se que oaprendizado das Ciências Biológicas, Químicas, Físicas e Matemáticas deve ter um caráter amplo, interdisciplinar ou transdisciplinar, contextualizado com a vida ${ }^{5}$ e voltado para a "formação cidadã de sentido universal e não somente de sentido profissionalizante" (p. 4). Especificamente no que diz respeito à Biologia e ao estudo do corpo humano, o texto enfatiza que o professor de Biologia deve privilegiar, dentre muitos outros aspectos, "o estudo das funções vitais básicas, realizadas por diferentes estruturas, órgãos e sistemas, comcaracterísticas que permitem sua adaptação nos diversos meios, possibilita a compreensão dasrelações de origem entre diferentes grupos de seres vivos e o ambiente em que essas relaçõesocorrem" (BRASIL, 2000, p, 18). Nesse sentido, tal como Santos (1998) menciona para o corpo humano comumente ensinado na escola e tão presente (ainda) nos livros didáticos de Ciências e Biologia, o corpo representado pelos PCNEM do Ministério da Educação é, antes de qualquer coisa, um organismo eminentemente biológico, sem as

\footnotetext{
${ }^{4}$ Disponível em: http://portal.mec.gov.br/seb/arquivos/pdf/ciencian.pdf, acesso em 05/10/2013.

${ }^{5}$ Afirma-se isso em função do que o documento menciona, à página 6: "os objetivos do Ensino Médio em cada área do conhecimento devem envolver, de forma combinada, o desenvolvimento de conhecimentos práticos, contextualizados, que respondam às necessidades da vida contemporânea, e o desenvolvimento de conhecimentos mais amplos e abstratos, que correspondam a uma cultura geral e a uma visão de mundo" (BRASIL, 2000, grifos das autoras).
} 
dimensões atribuídas à cultura (por exemplo, a estética, a sexualidade). Mas os PCNEM também apontam, de passagem, a importância de se dar destaque

às relações que se estabelecem entre os diferentes aparelhos e sistemas e entre o corpo e o ambiente,conferindo integridade ao corpo humano, preservando o equilíbrio dinâmico que caracteriza oestado de saúde. Não menos importantes são as diferenças que evidenciam a individualidade decada ser humano, indicando que cada pessoa é única e permitindo o desenvolvimento de atitudes derespeito e apreço ao próprio corpo e ao do outro (BRASIL, 2000, p. 18).

É notável que, no documento em questão, não há nenhuma menção à necessidade de abordagem, no Ensino Médio, de questões relacionadas ao gênero e à sexualidade. Já nas Orientações Educacionais Complementares aos Parâmetros Curriculares Nacionais ${ }^{6}$ - o chamado comumente de "PCN+" (BRASIL, 2007), como também nas Diretrizes Curriculares Nacionais (BRASIL, 2010), há brevíssimas alusões às discussões envolvendo gênero e sexualidade. Na página 34 do "PCN+", por exemplo, o documento retoma algumas habilidades que os alunos devem desenvolver já nos ciclos finais do Ensino Fundamental, quais sejam: sistematizar as concepções científicas relacionadas aos seres vivos, ao ambiente, ao corpo humano, à qualidade de vida das populações e aos sistemas tecnológicos; entender a história evolutiva dos seres vivos; caracterizar a diversidade da vida no planeta; reconhecer situações e ações de desequilíbrio ambiental e, também, ampliar "suas capacidades de valorizar os cuidados com o próprio corpo, de entender que a sexualidade é algo inerente à vida e à saúde e de compreender que boas condições de moradia, saneamento, trabalho, transporte, lazer, alimentação são essenciais para o bem-estar de todos nós, tanto quanto a ausência de doenças" (BRASIL, 2007, p. 34).

Em outra parte do referido documento são fornecidos exemplos explicativos para cada uma das competências gerais estabelecidas pelos PCNEM. Assim, para que os alunos possam se posicionar criticamente em relação a temas da ciência e da tecnologia, o texto aponta, como possibilidade metodológica, a análise de como os textos didáticos, as revistas, os jornais, os programas de tevê e de rádio "tratam questões relativas à sexualidade como as questões de gênero, as expressões da sexualidade, as relações amorosas entre jovens, as doenças sexualmente, transmissíveis, distinguindo um posicionamento isento, bem fundamentado do ponto de vista científico, da simples especulação, do puro preconceito ou de tabus" (p. 38). Essa proposta, retirada dos $\mathrm{PCN}+$, será explorada nesta seção da seguinte forma: num primeiro momento, analisase o modo como alguns livros didáticos inscritos no Edital do último Programa Nacional do Livro Didático - Biologia (PNLD 2012) representam a mulher, os relacionamentos homoafetivos e, também, outros aspectos relacionados à sexualidade 7 . Depois, consideram-se algumas iniciativas na formação de professores de Ciências e Biologia, no Ensino Superior, mostrando limites e (im)possibilidades.

\footnotetext{
${ }^{6}$ Disponível em http://portal.mec.gov.br/seb/arquivos/pdf/CienciasNatureza.pdf, acesso em 05/10/2013.

7 Uma de nós participou do PNLD 2012 Biologia na qualidade de avaliadora de coleções de livros didáticos (Ensino Médio). Como a avaliação é cega (o avaliador não tem acesso aos dados da editora e dos autores das coleções didáticas), não é possível indicar a qual livro ou coleção pertencem os exemplos citados nesta seção. Trata-se, assim, de um excerto do parecer parcial da avaliação (que não corresponde, necessariamente, ao parecer final exarado pela Coordenação Geral do Programa).
} 


\section{NOS LIVROS DIDÁTICOS}

Em um dos livros didáticos analisados, em uma seção chamada "Biologia em todos os tempos", focaliza-se a distribuição populacional da Síndrome de Down. Após uma série de informações históricas sobre a síndrome, bem como a caracterização da mesma em termos cromossômicos e clínicos, o livro traz uma tabela que "mostra a probabilidade de nascimentos de pessoas com síndrome de Down em diferentes grupos etários de mulheres" (LIVRO 1, s/d). A tabela tem, na primeira coluna, a informação "mãe (idade)", com distribuições que vão dos 15 aos 19 anos; dos 20 aos 24 anos, dos 25 aos 29 anos; 30 anos; 32 anos; 34 anos; 36 anos. Na segunda coluna, a informação "crianças com Síndrome de Down" é, na verdade, a proporção de nascimentos tendo em vista as idades maternas já referidas; na terceira e quarta colunas, as informações mostram a proporção de nascimentos de crianças afetadas em mães de 38 anos de idade (1/175) até a proporção de 1/25 em mães de 45 anos ou mais de idade.

O principal problema, nesse caso, é a omissão da informação de que pode haver a não disjunção (isto é, não separação) dos cromossomos 21 durante a formação de gametas na meiose de qualquer um dos genitores. Ao omitir essa informação, há a responsabilização (única e exclusiva) da mulher pelo nascimento de crianças afetadas pela síndrome. Assim, a síndrome passa de "acidente" ou, ainda, de "evento" da natureza para "culpa da idade materna" (isto é, do indivíduo). A idade materna considerada "avançada" (e, portanto, considerada "arriscada") para se ter filhos é a partir dos 35 anos (pelo menos, é o que afirmam os discursos biomédicos), mas é importante ressaltar que há vários estudos que já colocam em xeque tal entendimento - já que mulheres de 35 anos geralmente possuem mais recursos (financeiros, emocionais) e tendem a fazer mais exames médicos, a fazer mais exames pré-natais, etc.

Trata-se de um exemplo da prevalência dos discursos relacionados ao risco e das inúmeras práticas contemporâneas de promoção da saúde (os procedimentos de vigilância direcionados às mulheres, por exemplo) que, seja na mídia de uma maneira mais ampla, seja na escola ou nos livros didáticos, atuam sobre os sujeitos, seus corpos e subjetividades. O risco de ter uma criança com Síndrome de Down, no livro, é representado como um fato científico, como uma certeza mostrada de modo matemático e, mais: como uma verdade "didatizada", para que os alunos e alunas do Ensino Médio possam facilmente entender e incorporar em suas práticas adultas futuras. Mas é importante salientar que, desde a perspectiva dos Estudos Culturais e dos Estudos de inspiração Foucaultiana, não há essa coisa chamada "risco": trata-se de um discurso que envolve o ordenamento da realidade, transformando-a em algo calculável (DEAN, 1999). Além disso, o risco é uma forma de se representar os eventos de modo a torná-los manejáveis e governáveis - e, portanto, serviria como uma forma de atuação pedagógica sobre os indivíduos, a coletividade e as populações. É por isso que, para muitos autores (NELKIN, 1989; LUHMANN, 1996; LUPTON, 1999; DEAN, 1999; GIDDENS, 2002), o risco é uma construção cultural e uma tecnologia moral voltada para o manejo dos sujeitos. Se a gravidez na adolescência é cercada de atenção, riscos e cuidados nos livros (e a incrível centralidade dos métodos contraceptivos demonstra tratar-se de uma "transgressão social" e de uma "falha moral"), ao mostrar que a gravidez de mulheres acima dos trinta e cinco anos é "arriscada", o livro, de maneira perversa, também configura o fato como uma perigosa transgressão social e moral - pois afetaria econômica e geneticamente a população.

Em outro livro (LIVRO 2), foi encontrada uma seção voltada à exposição do tema "relacionamentos homoafetivos", além de muitas indicações de filmes para uma suposta 
"atualização" dos professores e professoras no que diz respeito às questões de gênero e sexualidade $^{8}$ ). Por um lado, a abordagem de tais assuntos pelos livros didáticos pode ser consideradapositiva, já que dá visibilidade à diversidade de modos de ser, de viver e de expressarse sexual e afetivamente. O Edital do PNLD Biologia, nesse aspecto, considera que a obra deve ser eliminada do acervo se não divulgar "conhecimentos biológicos para a formação de atitudes, posturas e valores que eduquem cidadãos no contexto de seu pertencimento étnico-racial (...) e de relações de gênero e sexualidade para interagirem na construção de uma nação democrática, em que todos, igualmente, tenham seus direitos garantidos e sua identidade valorizada".

Contudo, as imagens que ilustravam tal seção do livro contavam outra história: ao mostrar apenas rapazes e moças de mãos dadas, bem como homens e mulheres segurando crianças no colo (dando a entender, com isso, que se trata de um núcleo familiar), o livro visualmente reforçava aspectos relacionados à heteronormatividade, apesar de mencionar, no texto, os relacionamentos homoafetivos. Algumas explicações possíveis para esse aparente descompasso entre texto e imagem poderiam ser levantadas (inclusive, se pensarmos que as ilustrações, em um livro didático, são escolhidas por outros profissionais e não necessariamente pelos autores dos textos escritos), maspermanece a impressão de que a força de uma imagem mostrando um casal homossexual e feliz é intolerável dentro do ambiente escolar.

Em outro livro didático voltado ao Ensino Médio, a presença de um box voltado para alertar os jovens acerca da ocorrência de possíveis situações de assédio e abuso sexual dentro e fora da escola foi tida como extremamente positiva e necessária. Os alunos e alunas eram instruídos a procurar a ajuda dos pais, dos professores, da equipe diretiva da escola e, em última instância, a denunciar qualquer ação ao Conselho Tutelar da região.

\section{NOS CURSOS DE FORMAÇÃO DE PROFESSORES}

Por ministrarmos, no ensino superior, disciplinas em cursos de formação de professores, enumeraremos e descreveremos, a seguir, uma série de atividades voltadas para a sensibilização desses sujeitos no que diz respeito às temáticas focalizadas no presente artigo.

Como vimos anteriormente, há pequenos pontos de escape com relação às temáticas de gênero e sexualidade nos livros didáticos de Biologia - mas há, também, alguns exemplos que contribuem para a perpetuação de situações de preconceito e de exclusão. De qualquer forma, em grande parte dos livros analisados, verificou-se a existência de abordagens ainda muito "tradicionais", restritas a questões eminentemente conteudistas (nomeação de órgãos, tecidos e células dos sistemas genitais; apresentação de fenômenos biológicos associados) ou, ainda, fortemente apartadas das culturas e dos cotidianos (por exemplo, explicações meramente biológicas - hormonais, cerebrais - para o "desejo"; esclarecimentos acerca do desenvolvimento dos seios, da alteração vocal dos meninos, do crescimento diferenciado entre homens e mulheres, das diferenças biológicas entre eles e elas, etc.). Os professores em formação são, então, instados a pensar sobre tais aspectos e a analisar criticamente alguns dos materiais tradicionalmente utilizados nas salas de aula da educação básica (livros didáticos, paradidáticos, atlas,

\footnotetext{
${ }^{8}$ Filmes como Minha vida em cor-de-rosa (Mavieen rose, Alain Berliner, França, 1997), Juno (Juno, Jason Reitman, Estados Unidos, 2007), A cor púrpura (The color purple, Steven Spielberg, Estados Unidos, 1985) e Billy Elliot (Billy Elliot, Stephen Daldry, Estados Unidos, 2000), por exemplo, foram algumas das indicações dadas pelos autores de alguns livros didáticos de Biologia no Manual do Professor.
} 
documentários, filmes, livros infantis e infanto-juvenis, etc.), verificando como tais materiais constroem determinadas representações sexualizadas e generificadas. Esta é uma tarefa importante, mas que, em geral, mostra-se bastante difícil.

Além disso, os licenciandos também são convidados a problematizar artefatos culturais e midiáticos cotidianos que participam da construção de modos de ser homem e mulher contemporaneamente - como, por exemplo, o funk "Você Quer?", cantado e interpretado pela "Mulher Melão", cuja letra se encontra abaixo:

\section{VocêQuer? \\ Mulher Melão}

Você, você, você, você, você, você, você quer? Você, você, você, você, você, você, você quer? Você, você, você, você, você, você, você quer? Você, você, você, você, você, você, você quer?

\section{Você quer?}

Você quer? Você quer? Você quer? Você quer? Paga pra mim

Você quer? Você quer? Você quer? Você quer? Paga pra mim

Você quer? Você quer? Você quer? Você quer? Paga pra mim

Eu sou a Mulher Melão

O meu ritmo é assim

Paga pra mim, paga pra mim, paga pra mim

Paga pra mim, paga pra mim, paga pra mim

Quero por silicone Quero carro importado

Quero cordão de ouro

Quero roupa de marca

\section{Eu vou te seduzir}

Eu vou te deixar louco

Vou fazer você gastar todo dinheiro do seu bolso

Você, você, você, você, você, você, você quer? Você, você, você, você, você, você, você quer? Você, você, você, você, você, você, você quer? Você, você, você, você, você, você, você quer?

Quer? Você quer?

Você quer? Você quer? Você quer? Você quer? Paga pra mim

Você quer? Você quer? Você quer? Você quer? Paga pra mim

Você quer? Você quer? Você quer? Você quer? Paga pra mim

Mas eu não sou mercenária Os homens é que são "facinho" Fazem o que as mulheres querem Só pra ter nosso corpinho Só pra ter nosso corpinho

Paga pra mim, paga pra mim, paga pra mim

Paga pra mim, paga pra mim, paga pra mim

Fonte: http://www.vagalume.com.br/mc-frank-e-mulher-melao/voce-quer.html, acesso em 19 out 2015

Dentre os artefatos analisados também estão trechos de livros e filmes como, por exemplo, "A Bela e a Fera". Nessa história um dos personagens principais, Gaston, é admirado por muitos membros da aldeia em que vive (tanto homens, como mulheres). Ele é forte e viril. Além disso, ele não admite ser criticado e nem sair perdedor em coisas simples, tal como num jogo de xadrez. Quando tais situações acontecem, a solução que ele encontra é partir para a briga, utilizando-se de sua força física. Ademais, apesar de ser apaixonado pela Bela, ele a critica e a considera estranha, uma vez que "ela tem mania de leitura", atitude que segundo ele não é bom, já que em função dessa mania "ela pode começar a pensar e a ter ideias".

Tanto no funk da "Mulher Melão" quanto na história "A Bela e a Fera", o que se prioriza, em relação à mulher, parece ser o corpo. Se ela tiver um corpo bonito, qual a necessidade de ler, de pensar e de ter ideias? Além disso, também é importante questionar: o que a existência de uma cantora sem nome ("mulher") reduzida ao nome de "melão" em função de suas formas corporais 
nos mostra, em termos de pertencimento cultural? O que a letra da música nos diz acerca dos papéis de homens e mulheres - de "homens facinhos" que pagam (silicone, carro importado, cordão de ouro, roupa de marca) para ter uma "mulher corpinho"?

Procuramos problematizar esses artefatos com os licenciandos com os quais atuamos na tentativa de desnaturalizardeterminados significados usualmente atribuídos a homens e mulheres na nossa cultura. Entretanto, mesmo entre alunos de Ensino Superior, desenvolver tais atividades não se mostra uma tarefa simples, pois - muitas vezes - o que ainda "vale mesmo" é o que se vincula aos conhecimentos científicos, aos dogmas, às leis e às definições que contenham uma suposta verdade. Porém, a partir das perspectivas de onde falamos, não existem verdades únicas e absolutas, mas, sim, conhecimentos que precisam - constantemente - ser problematizados e discutidos.

\section{REFERÊNCIAS}

1. BRASIL. Parâmetros Curriculares Nacionais do Ensino Médio Parte III - Ciências da Natureza, Matemática e suas Tecnologias. Brasília: DF, 2000. Disponível em: http://portal.mec.gov.br/ seb/arquivos/pdf/ciencian.pdf, acesso em 05/10/2013.

2. BRASIL. Orientações Educacionais Complementares aos Parâmetros Curriculares Nacionais PCN+. Brasília: DF, 2007. Disponível em: http://portal.mec.gov.br/seb/arquivos/pdf/Cien ciasNatureza.pdf, acesso em 05/10/2013.

3. BRASIL. Diretrizes Curriculares Nacionais Gerais para a Educação Básica. Brasília: DF, 2010. Disponível em: http://portal.mec.gov.br/index.php?option=com_content\&id=12992:diretri zes-para-a-educacao-basica, acesso em 30/09/2013.

4. COSTA, M. Quem são? Que querem? Que fazer com eles? Eis que chegam às nossas escolas as crianças e os jovens do século XXI. In: MOREIRA, Antônio; ALVES, Maria Palmira; GARCIA, Regina (Orgs.). Currículo, cotidiano, e tecnologias. Araraquara: Junqueira\& Marin, 2006.

5. DEAN, M. Governmentality. Power and rule in modern society.London, Thousand Oaks, New Delhi: Sage Publications, 1999.

6. FOUCAULT, M. História da sexualidade 1: a vontade de saber. 12 ed. Rio de Janeiro: Graal, 1997.

7. GIDDENS, A. Modernidade e Identidade.Rio de Janeiro: Jorge Zahar Ed., 2002.

8. GREEN, B. e BIGUM, C. Alienígenas na sala de aula. In: SILVA, Tomaz Tadeu. Alienígenas na sala de aula: uma introdução aos estudos culturais em sala de aula.8 ed. RJ:Vozes, 2009.

9. HARAWAY, D. "Gênero" para um dicionário marxista: a política sexual de uma palavra. CadernosPagu, n. 22, 2004, p. 201-246.

10. LOURO, G. Gênero, Sexualidade e Educação:uma perspectiva pós-estruturalista. Petrópolis, RJ: Vozes, 1997.

11. Um corpo estranho: ensaios sobre sexualidade e teoria queer. Belo Horizonte: Autêntica, 2004.

12. LUHMANN, N. El concepto de riesgo. In: BERIAIN, J. (comp.). Las consecuencias perversas de la modernidad. Modernidad, contingencia y riesgo. Barcelona: Anthropos, 1996. 
13. LUPTON, D. Risk. London/New York: Routledge, 1999.

14. NELKIN, D. Communicating technological risk: The social construction of risk perception.Annu. Rev. Public Health, v.10, 1989, p. 95-113.

15. NELSON, C.; TREICHLER; P.; GROSSBERG, I. Estudos Culturais: uma introdução. In: SILVA, T.T. (Org.). Alienígenas na sala de aula. Uma introdução aos Estudos Culturais em Educação. Rio de Janeiro: Vozes, 1995.

16. SANTOS, L. H. S. Incorporando "outras" representações culturais de corpo na sala de aula. In: OLIVEIRA, D. L. (Org.). Ciências nas salas de aula.2a Edição. Porto Alegre: Mediação, 1998.

17. SCOTT, J. Gênero: uma categoria útil de análise histórica. Educação e Realidade. Porto Alegre: FACED/UFRGS, v. 20, n. 2, jul./dez. 1995, p. 71-99.

18. WEEKS, J. O corpo e a sexualidade. In: LOURO, G. L. (Org.). O corpo educado: pedagogias da sexualidade. Belo Horizonte: Autêntica, 1999, p. 35-82.

19. WILLIS, S. Cotidiano: para começo de conversa. Rio de Janeiro: Graal/Paz e Terra, 1997.

20. WORTMANN, M.L.C. Análises culturais - um modo de lidar com histórias que interessam à educação. In: COSTA, M. (Org.) Caminhos investigativos II: outros modos de pensar e fazer pesquisa em educação. Rio de Janeiro: DP\&A, 2002. 